\title{
ZNAČAJ PROMOCIJE ZA ODRŽIVI RAZVOJ KULTURNOG TURIZMA U FUNKCIJI ZAŠTITE SRPSKE KULTURNE BAŠTINE NA KOSOVU I METOHIJI
}

\author{
Ljiljana Stošić Mihajlović
}

\begin{abstract}
Sažetak
U savremenom svetu kulturni turizam je prepoznat kao važan činilac ekonomskih i društvenih promena. Posebno je evropska kulturna baština jedna od najstarijih i najvažnijih generatora turizma. Kulturne prestonice Evrope razvijaju svoje turističke strategije zasnovane na promociji kulturne baštine, što vodi ka ubrzanom rastu mnogobrojnih kulturnih atrakcija i razvoju kulturnog turizma. Naime, mnoge države u Evropi i širom sveta koriste kulturno nasleđe za privlačenje turista, pa su tako brojne destinacije prepoznate po tim mestima. Ermitaž u Sankt Peterburgu, Tadž Mahal u Indiji, Sagrada Familija u Barseloni, Tauer Bridž i Big Ben u Londonu, Karlov most u Pragu..., danas su neke od najposećenijih atrakcija u svetu. U vezi sa tim, kada je reč o razvoju kulturnog turizma u Srbiji, potrebno je identifikovati barijere i potencijale razvoja ovog vida turizma, kao i oblike održivog korišćenja kulturnih znamenitosti i dobara, posebno na teritoriji Kosova i Metohije. Osim promocije i očuvanja kulture, ovaj vid turizma omogućava restauraciju, očuvanje i zaštitu kulturno-istorijskih lokacija kroz održivi razvoj, od čega i lokalna zajednica može imati višestruke koristi.
\end{abstract}

Ključne reči: Marketing promocija, kulturni turizam, kulturna baština, Kosovo i Metohija

Akademija tehničko-vaspitačkih strukovnih studija, Niš

e-mail: stosicmihajlovicljiljana@gmail.com 


\title{
THE IMPORTANCE OF PROMOTION FOR SUSTAINABLE DEVELOPMENT OF CULTURAL TOURISM IN THE FUNCTION OF PROTECTION OF SERBIAN CULTURAL HERITAGE IN KOSOVO AND METOHIJA
}

\begin{abstract}
In the modern world, cultural tourism is recognized as an important factor in economic and social change. Especially the European cultural heritage is one of the oldest and most important generators of tourism. The cultural capitals of Europe are developing their tourism strategies based on the promotion of cultural heritage, which leads to the accelerated growth of numerous cultural attractions and the development of cultural tourism. Namely, many countries in Europe and around the world use cultural heritage to attract tourists, so many destinations are recognized in those places. The Hermitage in St. Petersburg, the Taj Mahal in India, the Sagrada Familia in Barcelona, Tower Bridge and Big Ben in London, Charles Bridge in Prague, .. today are some of the most visited attractions in the world. In this regard, when it comes to the development of cultural tourism in Serbia, it is necessary to identify barriers and potentials for the development of cultural tourism, as well as forms of sustainable use of cultural sights and goods, especially in Kosovo and Metohija. In addition to the promotion and preservation of culture, this type of tourism enables the restoration, preservation and protection of cultural and historical sites through sustainable development, from which the local community can have multiple benefits.
\end{abstract}

Keywords: Marketing promotion, cultural tourism, cultural heritage, Kosovo and Metohija

\section{UVOD}

Problem istraživanja ovog rada usmeren je na pitanje: „Kako kreirati savremene alate promovisanja kulturnog nasleđa Kosova i Metohije (KiM) u funkciji održivog razvoja turističke ponude, i to na način na koji doprinosi unapređenju turizma kao privredne grane i opštem ekonomskom i društvenom napretku, imajući na umu brojne aktuelne probleme u zaštiti srpskog kulturno-istorijskog nasleđa, nastale nakon jednostranog proglašenja nezavisnosti Kosova, 17. februara 2008. godine?" U radu je istaknuta potreba da se sa teorijskog, ovaj problem pretoči u dnevne aktivnosti svih donosioca odluke, prvenstveno o tome koliko uništavanje kulturno-istorijskog nasleđa srpskog naroda može biti ukupno 
štetno, za budući rast i razvoj turizma i privrede. Naučna opravdanost rada sastoji se u tome da, osim problema donošenja odluke, $u$ akademskoj zajednici treba inicirati da izvršna vlast preispita odluke koje se odnose na način zaštite i promocije kulturnog nasleđa. Metodologija korišćena u ovom radu je u skladu sa potrebama istraživanja u društvenim naukama. Korišćeni su brojni primarni i sekundarni izvori i dostupne elektronske baze podataka iz zemlje i sveta. Važno je istaći da je tema značajna, s obzirom na brojne i različite stavove zainteresovanih strana o adekvatnosti načina očuvanja srpskog kulturnog i istorijskog nasleđa na KiM, kao i budućim pravcima razvoja kulturnog turizma.

Poznati arheološki lokaliteti, tradicionalne svetkovine, kosovski vez, ali i specifični kosovsko-metohijski folklor i govor, jesu kulturne i turističke vrednosti koje postoje na teritoriji ovog dela Srbije. Ipak, da bi se ostvarila ekonomska korist od ove vrste turizma, pogotovo u kontekstu postojeće političke situacije, potrebno je doneti strateške dokumente koji će se fokusirati na ovaj segmet turizma i privući brojnije turiste. Ne moraju samo oni koji su zaduženi za kulturnu baštinu da promišljaju o načinima da promovišu, privuku i uključe posetioce u sadržaj, već postoji i jasno ukrštanje sa načinom na koji prvenstveno škole tretiraju kulturnu baštinu. Čini se i da škole u Srbiji, po svom institucionalnom obliku, nisu vične tome da učenicima na kompetentan način prenesu vrednosti srpske kulturne baštine na KiM. Neophodan je sistemski pristup u promociji srpske kulturne baštine, posebno na KiM. Primer dobre prakse je Finska projektom "Kulturni turizam i održivi razvoj", koja je donela turističku politiku, strateški dokument čiji je cilj poboljšanje saradnje sektora turizma i kulture, investiranje u obrazovanje i istraživački rad, promociju turizma putem kulturnih itinerera i sl. Strategija razvoja turizma R. Srbije za peiod 2016-2025. postoji kao dokument, ali je fokusiran na prirodne turističke potencijale, dok su kulturni gotovo zanemareni. Osim toga $u$ ovom dokumentu je navedeno da "na osnovu rezolucije $1244 \mathrm{UN}-\mathrm{a}$, teritorija AP KiM nije obuhvaćena merama i aktivnostima predviđenih strategijom, ali će se pratiti stanje na turističkim područjima Metohije: Rusolija, Hajla, Peć, Koprivnik, Dečani, Maja Streoc, Marjaš, Đakovica, Nistrica, Prizren, i turističkom području Šar planine: Štrpce, Sirinićka i Sredačka župa, Gora i Dragaš" (Strategija Strategija razvoja turizma Republike Srbije za peiod 2016-2025., 4). Suštinski nedostaje bar načelna briga za turistička područja Kosova (Gračanica, Prilepac kod Novog Brda, Gazimestan,...) kao i bolja organizovanost i adekvatnija saradnja sektora kulture i sektora turizma, kao i bolje obučeni i kadrovi specijalizovani za kulturni turizam. Posebno zato što ova vrsta turizma pomaže lokalni ekonomski razvoj novcem koji turisti ostavljaju u restoranima, kafanama i hotelima, kupovinom suvenira, ulaznica i drugih lokalnih proizvoda.Takođe, razvoj kulturnog turizma direktno doprinosi povećanju lokalne zaposlenosti. Na Svetski dan turizma, 27. 
septembara 2020. godine, kulturni turizam se predstavlja kao novo tržište koje ekspanziju doživljava usled porasta obrazovnog nivoa stanovništva, koje preferira održivi razvoj, socijalnu koheziju, značaj evropskog jedinstva, istoriju i kulturu i otkrivanje manje poznatih destinacija kroz turističku promociju. Neophodan je državni sporazumu okviru programa Kulturne rute Saveta Evrope, što bi omogućilo institucijama i organizacijama iz naše zemlje da se uključe u navedenu inicijativu. Program je najvećim delom okrenut ka promociji kulturnog turizma, kroz dobijanje sertifikata "Kulturna ruta Saveta Evrope“ koji dodeljuje Evropski institut za kulturne rute. $U$ dosadašnjem periodu 33 kulturne rute, koje prolaze kroz više od 50 država su dobile ovaj sertifikat. Evropski institut za kulturne rute broji preko 1600 članica, organizacija i instutucija. (Cultural routes programme, https://www.coe.int/en/web/cultural-routes). Cilj programa je da demonstrira, putem putovanja kroz prostor i vreme, kako nasleđe različitih zemalja i kultura Evrope doprinosi zajedničkom kulturnom nasleđu. Evropski institut za kulturne rute daje logističku pomoć i promoviše kulturne rute koje su dobile sertifikat Saveta Evrope, a uspostavljeni su i programi mobilnosti studenata sa univerziteta koji su sastavni deo mreže, koji podrazumevaju posetu lokaliteta koji su sastavni deo sertifikovanih ruta. Istine radi, u uslovima pandemije izazvane korona virusom sve industrije koje se zasnivaju na međuljudskom kontaktu, kao i turizam uopšte, ozbiljno su ugrožene.

\section{O POJMU I ZNAČAJU ODRŽIVOG KULTURNOG TURIZMA}

Održivi razvoj podrazumeva opšti društveni razvoj kojim se svi postojeći resursi koriste na takav način da zadovoljavaju društvene potrebe uz dugoročno očuvanje resursa. Održivi razvoj ima četiri osnovne dimenzije: ekološku (prostorno envajeronmentalnu), ekonomsku, socijalnu (društvenu) i kulturnu održivost. Pojam održivog kulturnog turizma označava neraskidivu povezanost napora usmerenih i ka očuvanju baštine i ka dostizanju održivog razvoja (Krivošejev, 2014).

Održivi razvoj je razvoj koji zadovoljava potrebe sadašnjice, ne dovodeći u pitanje sposobnost budućih generacija da zadovolje vlastite potrebe.
Baština je ono što je nasleđeno od prošlih generacija, što se održava u sadašnjosti, i što će se podariti za dobrobit budućih generacija 
Pojam kulturni turizam je izuzetno širok i postao je krovni termin za širok spektar različitih aktivnosti koje uključuju umetnički, baštinski, istorijski, arheološki i etno turizam, pa i rekreativni i hobi turizam koji postaju "niše" sve šire shvaćenog kulturnog turizma (Jelinčić, 2009). Prema užem pristupu baštinski turizam je vezan samo za obilazak kulturne baštine, njeno proučavanje i uživanje u njoj. Ovako tretiran pojam baštinskog turizma može da se izjednači i sa u Francuskoj uobičajenim pojmom turizam sećanja (Tourisme de mémoire). Time se pod baštinskim turizmom podrazumeva jedan vid kulturnog turizma koji doživljaj posetilaca usmerava isključivo ka kulturno-istorijskim znamenitostima, njihovom značaju i ulozi koju su imali u istorijskim procesima (Krivošejev, 2014: 70). Prema definiciji Američke asocijacije za planiranje i menadžment kulturnih resursa, kulturni turizam podrazumeva posete osoba van domaće zajednice koje su potpuno ili delimično motivisane interesom za istorijske, umetničke, naučne ili druge ponude vezane za životni stil - kulturno nasleđe, koje nudi zajednica, region, grupa ili institucija (Hadžić, 2005). Svetska turistička organizacija definiše kulturni turizam kao putovanja osoba isključivo radi zadovoljenja kulturnih potreba kao što su studijska putovanja, poseta festivala, koncerata i drugih događaja, obilazak spomenika kulture, putovanja radi proučavanja prirode, folklora ili religijska putovanja. Uloga kulturnog turizma se ne može sagledati samo kroz motivaciju već je i iskustvo izuzetno značajan činilac: iskusivši kulturu, turista postaje edukovan i zabavljen, ima mogućnost da nauči nešto o značaju mesta i zajednice koju posećuje, njihovom nasleđu, kulturi i prirodnom okruženju. Njoj je srodna i definicija koja kulturni turizam ograničava na baštinski turizam i određuje ga kao praksu putovanja radi doživljavanja iskustava o istorijskim i kulturnim atrakcijama u cilju sticanja znanja o kulturnom nasleđu zajednice, na edukativni i prijatan način.

Pojam kulturnog turizma sjedinjuje u sebi pojmove kulture i turizma. Ako se ta dva pojma pokušaju zamisliti u nekom kontekstu, čini da su vrlo blisko vezani i da se vrlo dobro upotpunjuju. Jasno je da kultura i kulturna baština pridonose atraktivnosti neke turističke destinacije pa su često i preduslov turističkog izbora. Akademsko istraživanje teme kulturnog turizma počinje 80 . godina XX veka kako bi se na optimalan način iskoristili kulturni resursi u turizmu, kao i da bi se podigao kvalitet turističke ponude, ali i zaštita i očuvanje materijalne i duhovne kulture kao izraza identiteta neke zajednice. Masovni turizam sve više nestaje, a zamenjuju ga selektivni oblici turizma koji obuhvataju različite vrste turizma koje su namenjene ciljnim grupama. Razvoj kulturnog turizma je posledica nemogućnosti postojećih oblika da zadovolje želje i potrebe kupaca turističke ponude, tako da se javila potreba za širom lepezom turističke ponude. Najčešća definicija kulturnog turizma glasi: „Kulturni turizam označava kretanje ljudi koje je uzrokovano 
kulturnim atrakcijama izvan njihovog uobičajenog mesta stanovanja, s namerom sakupljanja novih informacija $\mathrm{i}$ iskustava kako bi zadovoljili svoje kulturne potrebe" (Richards, 1999: 64). Pojam kulturnog turizma treba analizirati s gledišta više naučnih disciplina: ekonomske (posebno marketinga i odnosa s javnošću), turističke, kulturološke i edukativne. Time se olakšava njegovo razumevanje, naročito zbog toga što navedene discipline podjednako učestvuju u oblikovanju osnovnog sadržaja i značenja pojma, ali pri tome nemaju zajednički jezik, jer svaka disciplina ima sebi svojstven naučni vokabular. $\mathrm{Na}$ osnovu navedenog, kulturni turizam je selektivni oblik turističkog potencijala, motivisan kulturnim i umetničkim resursima, vrednostima i sadržajima. Kulturni turizam predstavlja generator održivog razvoja, koji omogućava mestima koja nisu isključivo turistička, osmišljenim razvojnim strategijama, koje se temelje na lokalnim kulturno-umetničkim potencijalima, postanu zanimljiva turistima, ali i lokalnom stanovništvu (Đukić-Dojčinović, 2005). Kulturni turizam je poseban oblik turizma koji ovoj privrednoj grani nudi dugoročnu konkurentsku prednost. Turizam i kultura se prožimaju, a osmišljavanjem kulturno-turističkog proizvoda obogaćuje se osnovni proizvod, odnosno imidž odredišta, povećava potrošnja, dužina boravka turista i zadovoljstvo njihovim boravkom, iz čega proizilazi ponovna poseta, stimulira se lokalna i regionalna potražnja i otvaraju se mogućnosti razvoja novih tržišnih segmenata. Od turizma kultura dobija dodatni izvor prihoda, šire se tržišta i stvaraju novi segmenti posetioca, podstiče se profesionalno upravljanje kulturnim dobrima i njihov marketing, omogućuje se bolja kontrola nad korištenjem kulturnih potencijala, a među lokalnim stanovništvom stvara se bolji imidž kulture (Demonja, 2006: 11).

\subsection{Kulturne turističke rute}

Jedan od savremenih trendova u razvoju turizma, pogotovu baštinskog, vezan je za osmišljavanje i prezentaciju „upakovanih“ turističkih proizvoda kakve predstavljaju specijalizovane tematske turističke rute, odnosno ciljano putovanje osmišljeno radi obilaska različitih, ali srodnih baštinskih subjekata međusobno povezanim istim ili sličnim temama i kontekstima, koji daju smisao celokupnom putovanju. Na taj način se doprinosi povezivanju srodnih baštinskih subjekata i njihovih destinacija i njihovom razvoju, što doprinosi i razvoju interkulturalnosti, širenju saznanja i popularizaciji, kao i umreženoj zaštiti baštine. Da bi jedna turistička ruta bila uspešna, neophodno je da ispuni sledeće uslove:

- Tematiziranost, odnosno jasno određivanje njene teme, kako bi se lakše pozicionirala u svesti potencijalnih putnika, prepoznala i brendirala; 
- Postojanje većeg broja tematskih atrakcija, ali i pojedinih netematskih atrakcija;

- Razvijenost turističke infrastrukture koja povezuje sve tematske atrakcije na ruti;

- Razvijenost sistema mapiranja i informativnog označavanja puta;

- Dobro osmišljen sistem komunikacija sa poseticima duž cele rute;

- Institucionalizovanu menadžersku i marketinšku povezanost svih atrakcija, putem formiranja klastera, udruženja i sl. (Maksin, 2010).

Prva zvanično proglašene Evropska ruta (1987) je put Camino de Santiago, dužine oko 800 km koji povezuje Španiju, Francusku i Portugaliju. Reč je o hodočasničkom putu "stopama Svetog Jakova“ čija je krajna tačka katedrala Santjago u Španiji. Hodočasnici koji najmanje 100 kilomerata pređu peške ili 200 kilometara biciklom, mogu da dobiju sertifikat o hodočašću (compostela). Značajno je da se naglasi da je ovaj put već 1993. godine registrovan kao Svetska kulturna baština. Glavne atrakcije na ovoj ruti su brojne crkve, spomenici, arheološki lokaliteti, pejzaži. Razvoju i popularnosti ove rute doprinelo je partnerstvo crkve i javnog i privatnog sektora. Po istom principu moguće je razviti slične rute kulturnog turizma na KiM.

\section{VREDNOVANJE KULTURNOG NASLEĐE KOSOVA I METOHIJE KAO TURISTIČKOG POTENCIJALA}

Kosovo i Metohija je prostor koji ima veoma bogatu kulturnu tradiciju i vredno kulturno nasleđe različitih etničkih grupa koje na njemu žive. Na teritoriji KiM živeli su vekovima Srbi, Albanci, Turci, Bošnjaci, Goranci, Hrvati, Romi, Egipćani, Aškalije, Cincari, Crnogorci i zajedno su kreirali specifično kulturno-istorijsko nasleđe koje kao takvo predstavlja značajan resurs za razvoj kulturnog turizma. Pikard ističe da se ovo nasleđe sastoji od spomenika arhitekture iz srednjeg veka, s crkvama i manastirima iz 14. veka koji su od međunarodne važnosti, do džamija i hamama iz 16. i 17. veka, manastirskih konaka iz 18. i 19. veka, do industrijskog nasleđa koje je u procesu identifikacije (Pickard, 2008). Zajednički suživot je doprineo prožimanju kulturnih uticaja, ali je pokazao i želju da se bude različit i insistira na „sopstvenom kulturnom identitu", mada smo sada svedoci da se kulturno nasleđe Srba sve više 
prikazuje kao nasleđe "kosovara" kako pripadnici albanske zajednice na KiM vole da ga određuju. Prostor na KiM ima značajne mogućnosti za razvoj turizma, ali je neophodno kreirati i odgovarajuće preduslove za održivi razvoj.

U svetu, turizam je postao značajna privredna grana što potvrđuju mnogi pokazatelji i izveštaji. Tako na primer, u Evropskoj uniji je u 2014. godini boravilo 58 miliona turista, a svaki jedanaesti zaposlen/a je radio u sektoru direktno ili indirektno vezanom za turizam, ukupno njih 9,7 miliona; pri čemu je prihod ostvaren u sektoru turizma činio $5 \%$ evropskog bruto društvenog proizvoda (World Travel Tourism Council, 2016). U svojoj suštini, turizam predstavlja kombinaciju ekonomskih i drugih celina, koje su povezane društvenom podelom rada, koja teži da stvori organizovanu ponudu svih proizvoda i usluga koje su neophodne za turiste koji povremeno borave van svog prebivališta. Ova ekonomska zavisnost je značajna u oblasti kulturnog turizma koji dobija sve veći značaj u ekonomiji i politici nakon svetske ekonomske krize. Što se tiče razvoja kulturnog turizma na teritoriji KiM je otežan u postojećim uslovima nerešenih političkih pitanja na ovom prostoru, bez obzira na mnogobrojne napore domaćih i međunarodnih aktera. Kulturni turizam se smatra razvojnom strategijom lokalnih vlasti koje se, na tom polju, suočavaju sa značajnim brojem problema.

Osmišljena strategija očuvanja kulturne baštine je osnov za razvoj kulturnog turizma. Valorizacija srpskog kulturno-istorijskog nasleđa na teritoriji Kosova i Metohije u funkciji turističke ponude predstavlja način da se stvori povoljna klima za razvoj kulturnog turizma, ali generalno i za bolji život svih naroda i etničkih zajednica i njihovo pomirenje nakon decenija sukoba na ovom prostoru (Radović i sar., 2018). Smatra se da je oružani sukob na Kosovu iz 1998/99. godine, poput mnogih savremenih oružanih sukoba, bio sukob zasnovan na identitetu, rezultat spora između različitih društvenih grupa organizovanih na principima zajedničke kulture. Ovaj element kulture u sukobu, pre svega dva naroda: Srba i Albanaca na KiM, prepoznat je i karakteru konflikta je dao novu formu (Kaldor, 1999).

Politika vrednovanja kulturnog nasleđa je i u skladu s mnogim dokumentima Evropske unije kakvi su na primer Strategija za pametan, održiv i inkluzivan rast i Strategija kulturnog nasleđa usvojena 2014. godine (EU Council, 2012), ali primena ovog pravnog okvira jeste težak zadatak za odgovorne na teritoriji KiM.

Na Listu svetske baštine iz Republike Srbije su do sada upisani segmenti nepokretne kulturne baštine sa teritorije Republike Srbije: Carska palata Felix Romuliana kod Zaječara, Bogorodičin manastir u Studenici, Stari Ras sa Sopoćanima /srednjovekovni utvrđeni grad Ras, manastir Svete Trojice u Sopoćanima i manastir Svetog Đorđa - Đurđevi Stupovi/, manastirski kompleks drevne Patrijaršije u Peći, manastir Vaznesenja Gospodnjeg u Dečanima, manastir Uspenja Presvete Bogorodice u Gračanici i crkva Presvete Bogorodice Ljeviške u Prizrenu. Poseban 
značaj je dat temi da „se ohrabre mladi ljudi da prepoznaju vrednosti kulturnog nasleđa“" (Openning Doors Newsletter on Northern Ireland's Built Heritage, 2012). Ne treba zaboraviti postojanje različitih kvalitativnih benefita kojima istorijsko nasleđe doprinosi razvoju ekonomije. Prema nekim autorima (Radović i sar., 2018: 5-15), to su:

- Privlačenje turista i kreiranje novih radnih mesta; Podsticaj ekonomiji (malim i srednjim preduzećima);

- Jačanje društvene kohezije zajednice; Jačanje kulturnog identiteta, ponosa zbog pripadanja svojoj zajednici;

- Kreiranje bezbednog zajedničkog prostora za sve pripadnike zajednice;

- Turizam kao važna polazna tačka za dalji ekonomski razvoj;

- Razvijanje veština mladih i njihove volonterske sklonosti i želje da ostanu u lokalnoj zajednici.

Tačno je da kulturno-istorijsko nasleđe na KiM nije osnova nacionalnog identiteta samo za Srbe, već je značajno za sve zajednice. S tim u vezi, poznato je da nacionalne i lokalne zajednice se u celom svetu ohrabruju da valorizuju kulturu koja predstavlja srž zajedničkog identiteta. Ipak, s obzirom na okolnosti, postupak valorizacije treba da se obavlja s posebnim senzibilitetom na teritoriji KiM imajući na umu tzv. vekovni konflikt između Srba i Albanaca, čije rešenje nije na pomolu u bliskoj budućnosti bez obzira na najave donosioci odluka u Republici Srbiji, Kosovu i međunarodnoj zajednici. Razlog za to je i svojatanje srpske kulturne baštine od strane tzv. republike Kosovo. U naporima da postanu ravnopravni član UNESKO, kosovske institucije su kreirale mnoga dokumenta, kojima potvrđuju navodnu opredeljenost za ravnopravnu zaštitu kulturnog nasleđa svih zajednica. Nacionalna strategija za kulturno nasleđe Kosova 2017-2027. kosovske vlade u oblasti kulturnog nasleđa, doneta je s ciljem "da uspostavi dugoročne okvire za viziju i pružanje rešenja zasnovanih na principu održivosti i sačinjena je u vezi sa opredeljenjem za članstvo u UNESCO što je Republika Srbija jednom već sprečila sa opravdanom argumentacijom da oni koji su sistematski uništavali i dalje nastavljaju da devastiraju srpsko kulturno, nasleđe ne mogu sebe da proglase za zaštitnike tog istog nasleđa. Zato je problem promocije za održivi razvoj kulturnog turizma u funkciji zaštite srpske kulturne baštine na Kosovu i Metohiji utoliko važniji. Važno je prepoznati specifičnost kulturnog nasleđa na način kako su to učinili Timoti i Bojd (Timothy \& Boyd, 2003) koji su istakli pojam zajedničkog kulturnog nasleđa na svim nivoima društvene organizacije, od lokalnog do globalnog i taj koncept treba da bude smernica za zaštitu kulturno-istorijskog nasleđa svake od etničkih zajednica koje žive na teritoriji KiM. 
Slika 1. Nivoi nasleđa

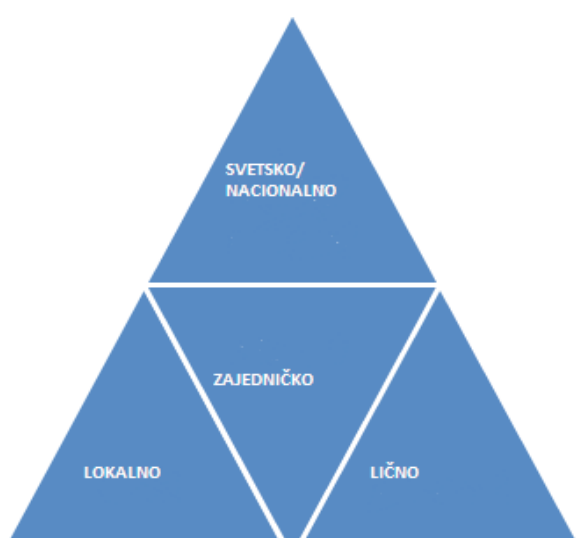

Izvor: Timothy \& Boyd, 2003.

Na KiM se nalaze brojni srednjovekovni hramovi Srpske pravoslavne crkve od kojih su četiri na Uneskovoj listi (United Nations Educational, Scientific and Cultural Organization - UNESCO) svetske baštine kao građevine koje su integrisale romaničke, romejske (vizantijske) i gotičke elemente korišćene u gradnji i ukrašavanju svetinja. Sakralno graditeljsko nasleđe na Kosovu i Metohiji obuhvata reprezentativne spomenike arhitekture srednjeg veka (Katanić, 2013). To su manastir Visoki Dečani, Pećka patrijaršija, crkva Bogorodice Ljeviške u Prizrenu i manastir Gračanica. Posebno je značajna uloga Srpske pravoslavne crkve u očuvanju sakralnih objekata na teritoriji KiM posle rata iz 1999. godine. Na osnovu podataka Srpske pravoslavne crkve iz 2003. godine, na KiM se nalazilo 1.300 srpskih pravoslavnih crkava i manastira. Opšte je poznato da je kulturno-istorijsko nasleđe na teritoriji KiM je za vreme oružanog konflikta 1999. ozbiljno stradalo. Pripadnici mirovne misije NATO obezbeđivali su 1999. godine najvažnije srpske pravoslavne manastire (Security Community, 2016). Ali, problem koje se odnosi na uništavanje srpskog nasleđa poslednje dve decenije je veoma aktuelan. Ridlmajeru svom izveštaju načinjenom neposredno nakon sukoba, u oktobru 1999.godine, gotovo zanemaruje uništavanje srpskog kulturnog nasleđa. Eskalacija nasilja na verskim i kulturnim objektima srpske zajednice se dešavala u više navrata i posle okončanja oružanog konflikta i u prisustvu međunarodnih predstavnika, a posledice tog uništavanja bile su katastrofalne. Slike uništavanja srpskog kulturnog nasleđa u etničkom nasilju - pogrom, marta 2004. godine izazvale su reakciju kulturne javnosti na globalnom nivou. Uništavanje srpskog kulturno-istorijskog nasleđa dešavalo i pre eskalacije oružanog sukoba: podmetnuti požari u manastiru Visoki Dečani i Pećkoj patrijaršiji 1982. godine, a nastala šteta je bila neprocenjiva. Ono što ohrabruje jeste činjenica da je nakon konflikta Organizacija za evropsku 
bezbednost i saradnju - OEBS prepoznala potrebu da se razviju „mehanizmi zaštite" kulturnoj i verskoj baštini svih etničkih i verskih.

Na Univerzalnom kulturnom forumu koji je održan u Barseloni 2004. godine istaknuta je uloga turizma koji treba da omogući prostor da "sve kulture mogu da se izraze i omoguće sebi da se drugi s njom upoznaju, kao i da ostvare interkulturalni dijalog koji vodi miru i uspostavljanju održivog razvoja" (Bouchenski, 2004: 5). Uloga srpskog kulturno-istorijskog nasleđa u izgradnji mirnog i demokratskog društva i u procesu održivog razvoja i promociji kulturne raznolikosti na teritoriji Kosova i Metohije jeste značajna i u skladu je sa Faro konvencijom (Savet Evrope, 2005). Na donosiocima političkih odluka je da pronađu način na koji će se ostvariti jednaka pravna i fizička zaštita kulturnog nasleđa srpske zajednice u cilju razvoja kulturnog turizma i očuvanja kulturne raznolikosti. Kulturna raznolikost i bogato kulturno-istorijsko nasleđe na teritoriji KiM osnovna su pretpostavka za razvoj kulturnog turizma. Kulturni turizam u Evropi i svetu dobija sve veći značaj u ekonomiji i politici zato što se u mnogim zemljama koristio i koristi kao faktor ekonomske strategije, ali i pomirenja u konfliktnim zonama (Radović \& Vojinović, 2017).

\section{KOSOVO I METOHIJA KAO BAŠTINSKA TURISTIČKA DESTINACIJA}

I pored toga što obiluje kulturno-istorijskim nasleđem, prostor KiM se ne može prepoznati kao značajna turistička destinacija, pri čemu aktuelna politička dešavanja ovu situaciju još otežavaju. Kosovo se prepoznaje kao crna tačka i moguće žarište novih sukoba na Balkanu. Postoje određeni napori da se KiM prepozna u međunarodnoj zajednici kao turistička destinacija, ali nerešen status ove pokrajine doprinosi tome da podataka o njemu nema na sajtovima najuglednijih međunarodnih organizacija u oblasti turizma, niti u njihovim godišnjim izveštajima.

Kosovo i Metohija je podeljeno na pet turističkih regiona: centralni region Prištine, turistički region Prokletija, region Šar planine, Pomoravlja, Kosovske Mitrovice i Bajgorske Šalje. Međunarodna zajednica koja još uvek kontroliše institucije na KiM pokušava da raznim aktivnostima doprinese da se ova teritorija prepozna kao nova turistička destinacija u Evropi. Poznati sajt za planiranje putovanja Tripadvajzor (Tripadvisor) u svojoj ponudi predlaže 39 hotela, 192 restorana i 84 objekta i lokacija koje treba posetiti prilikom boravka na Kosovu i Metohiji među kojima su i različite vrste turističkih sadržaja. S obzirom na značajno 
bogatstvo koje se ogleda u kulturno-istorijskim spomenicima na teritoriji Kosova i Metohije postoje osnovne pretpostavke za razvoj kulturnog turizma. Zbog potrebe očuvanja kulturno-istorijskog nasleđa i njegove prezentacije u oblasti kulture se ističe značaj kulturnih ruta, a tokom vremena se pokazalo da kulturni turizam koristi prostore koje pokrivaju kulturne rute $\mathrm{i}$ da ih veoma uspešno implementira u turističku ponudu (Matić, Zubanov \& Tomka, 2015). Primer ovakvog pristupa jeste i inicijativa koju je pokrenula Evropska unija i Savet Evrope za stvaranje Kulturne rute zapadnog Kosova, što predstavlja podršku promociji kulturne raznolikosti na Kosovu. Kulturna ruta zapadnog Kosova odnosi se na gradove: Junik, Đakovica, Peć, Klina, Dečane i Istok. Svaka od ovih opština imala je zadatak da definiše svoje potencijale koji čine deo zajedničkog nasleđa. Kulturna ruta zapadnog Kosova omogućila bi turistima da obiđu tradicionalne građevine, dožive i neposredno upoznaju lokalne kulturne običaje, uživaju u različitim gastronomskim specijalitetima i vinu, uživaju u prirodnim lepotama i sportskim aktivnostima u okruženju netaknute prirode. Raznolikost prostora KiM čini ga atraktivnim i pored evidentne činjenice da se ova teritorija i dalje smatraja nebezbednom za turiste, a bezbednost jeste kritičan elemenat izbora turističke destinacije. KiM svakako ima potencijal za razvoj verskog turizma. Integracija kulturnog nasleđa i turizma uključuje kulturu i istorijsku doslednost identiteta kroz istorijske, arheološke, umetničke, naučne i društvene vrednosti. KiM predstavlja kompletno kulturno okruženje koje obuhvata više grupa kulturnih vrednosti, kulturnih i tipičnih pejzaža, istorijskih gradova i utvrđenja. Ovu inicijativu treba podstaći kreiranjem novih turističkih proizvoda koji bi bili kvalitetni i dizajnirani i predstavljeni na bitno drugačiji način. Za razvoj KiM kao turističke destinacije potrebno je razviti osnovne promocione aktivnosti važne za pomenuti razvoj. Tu spadaju promocija destinacije, inoviranje načina rezervacije i kupovine turističkog proizvoda i obezbeđenje svih neophodnih informacija potencijalnim korisnicima usluga uz, naravno, podizanje svesti lokalnog stanovništva o značaju i važnosti razvoja turizma kao privredne grane, čime bi se možda i povećala bezbednost turista, jer atraktivnost turističke destinacije osim pristupačnosti čini i materijalna baza za razvoj turizma, koja je sada sasvim nezadovoljavajuća. U procesu osmišljavanja promocionih aktivnosti trebalo bi stalno imati na umu da KiM ima potencijal da u bliskoj budućnosti može postati turistička destinacija na kojoj će turisti imati priliku da se upoznaju sa kulturno-istorijskim nasleđem koje je jedinstveno u ovom delu Evrope i samim tim doprineti njegovom održivom razvoju, kroz očuvanje za buduće generacije. 


\section{PROMOVISANJE KULTURNOG NASLEĐA KOSOVA METOHIJE}

Pitanje promocije kulturnih vrednosti je veoma kompleksno, pre svega zato što su kultura i ekonomija, konkretno marketing kao ekonomska praksa i podsistem u sistemu ekonomskih nauka, u istoriji razvoja civilizacije često bile različito tumačene. Nerazumevanje između ekonomista i predstavnika kulturnog sektora, umetnika, osnivača i donosioca odluka neophodno je prevazići na način koji uvažava kulturne osobenosti, ali i uz ograničenja koja generiše ekonomska situacija jedne zemlje. Kultura u savremenom društvu treba da dokaže svoju vrednost na način koji je razumljiv donosiocima odluka. Promocija kulturnog nasleđa pokazaće prave društveno-kulturne, ekonomske i vrednosti kulturnog nasleđa KiM i sadrži sledeće mere i ciljeve:

1. Studiju i interpretaciju kulturnog nasleđa - odnosi se na interpretaciju društveno-kulturnih i ekonomskih vrednosti kulturnog nasleđa KiM; Povećanje broja objava, vodiča, virtuelnih medija itd i sistematska distribucija u zemlji i inostranstvu; Povećanje upotrebe digitalnih medija i internet mreža za promociju kulturnog nasleđa KiM.

2. Razvoj kulturnog turizma na osnovu principa održivosti - odnosi se na postizanje strateških pristupa za održivi razvoj turizma; Poboljšanje turističke infrastrukture, standardizacija i prostorni raspored na strateškim tačkama lokacijama na celoj teritoriji KiM; Stvaranje reprezentativne simbolike za lokacije kulturnog nasleđa; Promovisanje tradicionalne lokalne gastronomije kao turističkog proizvoda; Marketing i brendiranje značajnih kulturnih i socijalno - ekonomskih vrednosti kulturnog nasleđa i njihova promocija po globalnim principima održivog razvoja čime se stvara se platforma za razvoj održivog turizma u skladu sa svetskim principima i praksama usklađenim i podržanim u Evropskoj povelji (2007) i međunarodnim smernicama za održivi turizam, koje promoviše UNESCO. Prioritet programa je postavljanje reprezentativne simbolike koja će se koristiti za kreiranje brendova i marketing tradicionalnih proizvoda i značajnih vrednosti nasleđa. Budžetski prioritet će biti poboljšanje turističke infrastrukture (obeležavanje, info-centri, itd sa programskom podrškom Vlade Srbije i privremenih institucija na KiM, standardizacija informacionih tačaka po odabranom modelu i prostorne strateške distributivne linije/tačke (aerodromi, železničke autobuske stanice, gradski centri u saradnji sa lokalnim organima).

3. Promociju kulturne raznolikosti, poštovanje i zaštita nasleđa i kulturno izražavanje zajednica na KiM - mere se odnose na poštovanje i zaštitu nasleđa i kulturnog izražavanja zajednica KiM, bliska saradnja Srpskom pravoslavnom 
crkvom, kao i promovisanje konkretnih akcija, poštovanja i poverenja kao dodatnih vrednosti. Sprovođenje ovog cilja u velikoj meri zavisi od partnerstva o planiranju i razvoju inkluzivne interpretacije, prezentacije i komunikacije, marketinga i brendiranja kulturnog nasleđa u javnoj sferi i socijalnom i privatnom sektoru. Mere su uglavnom odnose na studiranje, tumačenje i objavljivanje studija i promotivnih materijala. Mere i propratne aktivnosti koje se odnose na razvoj kulturnog turizma zahtevaju koordinaciju aktivnosti sa Vladom Srbije i privremenih institucija na KiM (npr. otvaranje turističkih stranica za celu teritoriju Kosova i turističkih lokaliteta odvojeno, kao preduslov za povećanje korišćenja digitalnih medija i online mreže za promociju kulturnog nasleđa KiM). Sve to ima za cilj da promoviše kulturnu raznolikost kroz sveobuhvatnu distribuciju Konvencije UNESCO-a o kulturnoj različitosti. Prioritetna mera u tom pravcu je dalja saradnja sa Srpskom pravoslavnom crkvom, kao i poštovanje i zaštita nasleđa i kulturnog izražaja drugih zajednica na KiM. Promocija kulturnog turizma označava kreiranje preferencije i želje nekoga za određenom uslugom u specifičnom vremenskom trenutku. Podela kulturnih dobara na pokretna i nepokretna kulturna dobra veoma je važna za sam proces promocije, jer turističko ciljno tržište i nije isto za jedna ili druga dobra. Ono što se ogleda u praksi jeste da pored brojnih naglašavanja o važnosti promocije za razvoj turizma na KiM veće aktivnosti u ovoj oblasti izostaju. Zapravo, promocija je veoma skup proces i zahteva napore i sredstva zainteresovanih strana. Promociji kulturnog nasleđa prethodi njegova valorizacija, koja u slučaju KiM u potpunosti nedostaje.

\section{ZAKLJUČAK}

Kulturni turizam obuhvata i kulturu i turizam. Da bi se ta dva pojma nadovezala jedan na drugi važno je da u ponudi kulturnog turizma ima mnogo kulturne baštine. U radu je istaknuta važnost promocije za održivi razvoj kulturnog turizma u funkciji zaštite srpske kulturne baštine na Kosovu i Metohiji koja mora da počiva na prethodnoj urgentnoj valorizaciji kulturno-istorijskih dobara na teritoriji KiM. Ukazano je na značaj jačanja svesti brojnih zainteresovanih strana o potrebi kreiranja alata i modela koji su neophodni za njihovo prepoznavanje kao atraktivnog, savremenog i konkurentnog turističkog proizvoda. Potreba promocije je prepoznata u sadržaju strateških dokumenata, ali i dalje ostaje bez značajnije implementacije u praksi. Na KiM neophodno je da se proces promocije kreira na način koji će omogućiti da se očuva srpsko kulturno-istorijsko nasleđe i izbegne popularizacija nasleđa pojedinačne etničke grupe koja živi na toj teritoriji. 
Promocija bi trebalo da bude osmišljena tako da obuhvata brojne indikatore, zasnovane na valorizaciji kulturno-istorijskog značaja. Iskustva razvijenih zemalja u promociji kulturnih vrednosti, pre svega kulturno-istorijskog nasleđa, su od velikog značaja u ovom procesu koji nije lak, niti jednostavan zbog brojnih okolnosti, pre svega, politička nestabilnost i problema obezbeđenja neophodnih finansijskih sredstava.

Sam proces promocije treba da bude jasan i transparentan kako bi se izbegle dodatne teškoće i mogući animoziteti između etničkih zajednica. Promocija kulturnog nasleđa ne sme biti uslovljena dnevno-političkim dešavanjima, i može biti jednako pogubna za srpsko kulturno nasleđe na KiM ukoliko prestane finansiranje Republike Srbije i međunarodne zajednice za njegovo očuvanje. Način realizacije podrazumeva anuliranje negativnih političkih signala koji ukazuju na to da je srpsko nasleđe na KiM devastirano iz čisto etničkih ili verskih razloga. Promociju kulturno-istorijskog nasleđa u funkciji jačanja održive turističke ponude treba realizovati u skladu sa usvojenom normativno-pravnom regulativom i uz prihvatanje kriterijuma zaštite i očuvanja usvojenih u razvijenim demokratskim zemljama.

\section{LITERATURA}

1. Bouchenski, M. (2004). General Vice Director for Culture at UNESCO Universal Forum of Cultures Tourism Culture and Sustainable development

2. Vlada Republike Srbije. (2016). Strategija razvoja turizma RS za period 2016-2025

3. Demonja, D. (2006) Institutional network of cultural tourism. U: Leš T.P., Pletenac T. [ur.] Ethnology and Cultural Tourism, Zagreb: Faculty of Humanities and Social Sciences, Department of Ethnology and Cultural Anthropology, 11-15). ISBN: 86-7102-197-1

4. Đukić-Dojčinović, V. (2005). Kulturni turizam - menadžment i razvojne strategije, Beograd: Clio

5. Jelinčić D. A. (2009). Abeceda kulturnog turizma, Zagreb ISBN 9789537355180

6. Kaldor, M. (1999). New and Old Wars Organized Violence in a Global Era. Stanford: Stanford University Press, California.

7. Katanić, Z. (2013). Značaj kulturno-istorijskih spomenika Kosova i Metohije kao predmet turističke prezentacije sa posebnim osvrtom na njihov značaj u okviru svetske kulturne baštine. U: Grbić, N. (ured.) (2013). 7th.EUROBRAND (str. 92-101). Zrenjanin.

8. Krivošejev, V. (2014). Upravljanje baštinom i održivi turizam, Narodni muzej Valjevo, Artis Centar, Beograd ISBN: 978-86-84893-30-9 
9. Matić, S., Zubanov, V. \& Tomka, D. (2015). Kulturno-istorijsko nasleđe kao osnov za kreiranje kulturnih tematskih ruta na Petrovaradinskoj tvrđavi. Tims acta, 9(1), 15-24.

10. Maksin, M, Pucar, M., Korać, M., Milijić, S. (2010). Menadžment prirodnih i kulturnih resursa u turizmu, Beograd: Univerzitet Singidunum. ISBN: 978-86-7912-215-5

11. Ministarstvo kulture, omladine i sporta Kosova. (2017). Nacionalna Strategija zaštite kulturnog nasleđa 2017-2027.

12. Pickard, R. (Ed) (2008). Analysis and Reform of Cultural Heritage Policies in South - east Europe. Council of Europe.

13. Richards, G.: (1999).XVII EuropeanCulturalTourism: Patternsand Prospects. In: Planning Cultural Tourismin Europe; Boekman Foundation/Ministry of Education, Culture and Science, p. 17.

14. Radović. V., Katanić, Z., Pezo, L. (2018). Valorizacija srpskog kulturno-istorijskog nasleđa Kosova i Metohije. TIMS.Acta 12, 5-15. Novi Sad: Fakultet za sport i turizam

15. Radović, V. \& Vojinović, Ž. (2017). Development of innovative tourism product in rural areas: Challenges and security issues (pp.234- 254). Thematic Proceedings I University of Kragujevac, Faculty of hotel management and tourism in Vrnjacka Banja.

16. Riedlmayer, A. (2000). Monument and Crime: The Destruction of Historic Architecture in Kosovo. Grey room, 1(16), 108-122.

17. Timothy, D.J. \& Boyd, S.W., (2010). Heritage Tourism. Edinborough: Pearson education. Ltd. The National Trust for Historic Preservation in the UN

18. Hadžić, O. (2005). Kulturni turizam, Novi Sad: Prirodno-matematički fakultet, Departman za turizam i ugostiteljstvo

19. Cultural Routes Programme, https://www.coe.int/en/web/cultural-routes

20. Security Community. (2016). Osnova za mir, zaštita kulturne baštine na Kosovu. February 2016 by Paivi Nikander and Valeri Zirl. Dostupno na: http://www.osce.org/sr/

21. Faro Convention. (2005). The framework convention on the value of cultural heritage for society. Council of Europe Dostupno na: https://rm.coe.int/1680083746

22. World Travel Tourism Council.(2016). Travel \& Tourism Economic Impact 2016 World. Dostupno na: https://www.wttc.org/-/media/files/reports/economic\%20impact\%20 research

Рад је примљен: 28. јул 2020.

Прихваћен за објављивање: 31. август 2020.

Received: July 24, 2020.

Accepted: August 31, 2020. 